\title{
A meta-analytic study investigating the efficiency of socio-emotional learning programs on the development of children and adolescents
}

\author{
Alexandru Boncu $^{1 *}$, Iuliana Costea $^{1} \&$ Mihaela Minulescu $^{2}$ \\ ${ }^{I}$ Department of Psychology, West University of Timişoara, Romania \\ ${ }^{2}$ National School of Political Studies and Public Administration, Bucharest, Romania
}

Received 18.10.2017; Received revised 19.12.2017; Accepted 22.12.2017

Available online 31.12.2017

\begin{abstract}
The aim of the present study was to investigate the impact of Social Emotional Learning (SEL) programs on different youth behavioral outcomes. The previous meta-analysis on school-based SEL programs reported a small but significant effect of SEL on the emotional and behavioral outcomes. We found 33 articles with 37 studies, with 32742 subjects, comparing an intervention with a control group to assess the effect of SEL program. Results have shown a statistically significant effect size for programs delivering SEL $(\mathrm{g}=.31)$. Significant effect sizes were reported for specific outcomes involved in the analysis. Concluding, our meta-analysis supports the previous findings from the scientific literature regarding the impact of SEL programs. Practical implications are discussed.
\end{abstract}

Keywords: SEL, internalizing problems, externalizing problems, social and emotional skills.

Address of correspondence: Alexandru Boncu, Department of Psychology, West University of Timişoara, Bld. V. Pârvan nr. 4, Timișoara, 300233, Romania.

E-mail: alexandru.boncu@e-uvt.ro

\section{Introduction}

The progress recorded by science and technology is providing a better understanding of psychological problems faced by youth. Nowadays, specialists can approximate the distribution of a problem in the population and investigate the risk and protective factors related to the problem. For example, studies have reported that between $13 \%$ and $20 \%$ of children will suffer at least once in their lifetime of a psychological disorder (Perou et al., 2013). Moreover, researchers have pointed a multitude of factors influencing the mental health of youth. Some of these factors are family related and concerns the cohesion in the family (Finan, Schultz, Gordon, \& Ohannessian, 2015), communication (Ryan, Jorm, \& Lubman, 2010), and parental practices (Vaughn, Salas-Wright, DeLisi, \& Maynard, 2014). From school environment, mental health can be influenced by factors such as school connectedness (Resnik et al., 1997), bonding to school (Guo, Hawkins, Hill, \& Abbott, 2001), and school membership (Shochet, Dadds, Ham, \& Montague, 2006). Also, personal resources can be related to the development of psychological problems (e.g., self-efficacy, Klasen et al., 2015; selfesteem, Kerr \& Stattin, 2000; optimism, Bamford \&
Lagatutta, 2012). Regarding the factors mentioned above, specialists agree that prevention can provide an effective solution to the decrease of mental health problems.

Prevention of mental health problems in youth

Prevention of mental health problems has urged specialists and researchers to develop specific programs to deal with this issue. Prevention, as opposed to intervention, takes place before the disease or disorder occurs or in the early stages of their manifestation. It is also to be mentioned the interdisciplinary nature of prevention as a science that combines person's development with community epidemiology and the perspectives of preventive intervention (Cordova et al., 2014). Durlak and Wells (1997) found significant effects of the programs involved in a meta-analysis regarding social and emotional problems of youth, after conducting a meta-analysis concerning universal prevention programs. Examples of outcomes included in Durlak's meta-analysis include academic achievement, cognitive processes, internalizing and externalizing problems. Some of the most efficient prevention programs are delivered in schools. Mills et al. (2006) suggest that schools are the ideal environment for implementing programs to promote mental health and 
prevent the occurrence of emotional and behavioral disorders.

\section{Social Emotional Learning}

Social Emotional Learning (SEL) is one of the most used frameworks for prevention of emotional and behavioral problems in children and adolescents. SEL uses positive youth-development and the promotion of social and emotional competencies to prevent the development of emotional and behavioral problems (Benson, 2006; Guerra $\&$ Bradshaw, 2008). This concept has developed from the research related to prevention and resilience (Zins, Bloodworth, Weissberg, \& Walberg, 2004). Still, the interest for this type of learning has grown after the publication of Goleman's book (1995): Emotional Intelligence: Why it can matter more than IQ for character, health and lifelong achievement. SEL is based on five components (Weissberg \& Cascarino, 2013): selfawareness, self-management, social-awareness, relationships skills, and responsible decision making. The five competencies mentioned, are aiming to offer to youth a foundation for reducing conduct problems and emotional distress and also to increase academic performance and positive behaviors (Greenberg et al., 2003). Another key point in mastering the SEL competencies is the shift of the youth ability from an external control of their emotions and reactions to an internal one (Bear \& Watkins, 2006). Studies have shown that programs using SEL framework provided positive outcomes in children and adolescents. Regarding mental health problems, SEL programs proved efficient in reducing depression (Lewis et al, 2013; Schonert-Reichl et al, 2015), general anxiety (Bavarian et al., 2013), social anxiety (Coelho, Marchante, \& Sousa, 2015) and other emotional problems (Humphrey, Kalambouka, Wigelsworth, \& Lendrum, 2010; Muratori et al, 2015). Also, other studies reported an increase in social and emotional competencies (Bierman, Nix, Greenberg, Blair, \& Domitrovich, 2008; Caldarella, Christensen, Kramer, \& Kronmiller, 2009; Castillo, Salguero, Fernandez-Berrocal, \& Balluerka, 2013; Pendry, Carr, Smith, \& Roeter, 2014). Moreover, social and emotional learning programs have shown positive results in increasing academic performance in youth (Bradley, Galvin, Atkinson, \& Tomasino, 2012; Bavarian et al., 2013).

\section{Previous meta-analysis on SEL programs}

Our study is not the first of its kind. On the one hand, this meta-analysis is part of the scientific reviews concerning prevention programs related to mental health problems in youth. On the other hand, regarding a more specific area, this study is related to the scientific reviews investigating the efficiency of social and emotional learning programs. In a previous meta-analysis concerning the effectiveness of social and emotional learning programs delivered in schools (Durlak, Weissberg, Dymnicki, Taylor, \& Schellinger, 2011), results were promising. More specifically, the effect size was significant $(0.30)$. Moreover, in the same meta-analysis, we can see that SEL programs are effective in reducing emotional distress and conduct problems while increasing social and emotional skill, prosocial behavior and positive attitudes. Another meta-analysis investigating after-school programs that promote positive development (Durlak, Weissberg, \& Pachan, 2010) have also reported significant results. Although, the programs delivered after-school have proven to influence some outcomes, the effect sizes are smaller compared to programs provided in school. The results obtained in the meta-analysis of after-school prevention programs suggest that programs included in the educational curriculum can be more successful.

\section{Overview of the current study}

As we showed above, there are meta-analyses that have investigated the role of SEL programs in preventing different types of problems in the youth population. Still, the results obtained by the previous meta-analyses, although significant, have left open some questions regarding the potential impact of SEL programs on emotional and behavioral outcomes. First, the effect size obtained in the last meta-analyses is significant, nevertheless a small one. Second, there are still variables left out that can moderate the effect of these programs. Finally, the question arises: Have the SEL programs improved its efficiency since the last review made?

The current meta-analysis aimed to investigate: (1) to investigate the efficiency of SEL programs on reducing internalizing and externalizing problems and on the increase of social and emotional skills, prosocial behavior and attitudes towards self and others; (2) to investigate the potential influence of the age as moderator.

\section{Method}

\section{Literature search}

Potential relevant studies were identified after a systematic search of EBSCO, Psychinfo, and ERIC through August 2015. We used the following keywords: "social and emotional learning," "program," "trial," "training," "prevention," "intervention," "children" and "adolescents." Also, we researched the references to the most recent articles (Coelho et al., 2015; Schonert-Reichl et al., 2015) for potential studies using SEL programs.

\section{Selection Criteria}

The initial search revealed 147 articles. 24 duplicates were removed, and a total of 123 articles were screened. After the screening, 56 papers were excluded. Assessing for eligibility brought exclusion for another 34 studies due to several reasons: studies without a control group, studies involving population with specific problems, correlational studies, theoretical reviews, and studies with insufficient data for the analysis. Finally, 33 articles were included in the meta-analysis, consisting of 37 studies (see Figure 1).

\section{Inclusion Criteria}

The eligible studies for the inclusion in the metaanalysis had to be: (a) studies published in the interval of 1 January 2008 and December 2015; (b) articles written in English or in Spanish; (c) the subjects of the studies to be enrolled in the educational system, accepting from the preschool to the end of the high-school; (d) experimental or quasi-experimental studies with at least one control group; (e) dependent variables from the studies must meet the criteria of the categories mentioned in this paper; (f) studies eligible with at least one intervention specific to social and emotional learning; and (g) studies eligible should have passed thought a peer review process.

\section{Exclusion Criteria}

We excluded the studies containing subjects that were diagnosed with different psychological problems (clinical, behavioral, and emotional). Also, we excluded studies that 
aimed to improve positive development and mental health through prevention of ADHD, drug consume, risky sexual behaviors, premature pregnancy risk, alcohol consume. The reason behind the exclusion of these types of studies, even if they used SEL, stands with the aim of the activities that could target a specific problem.

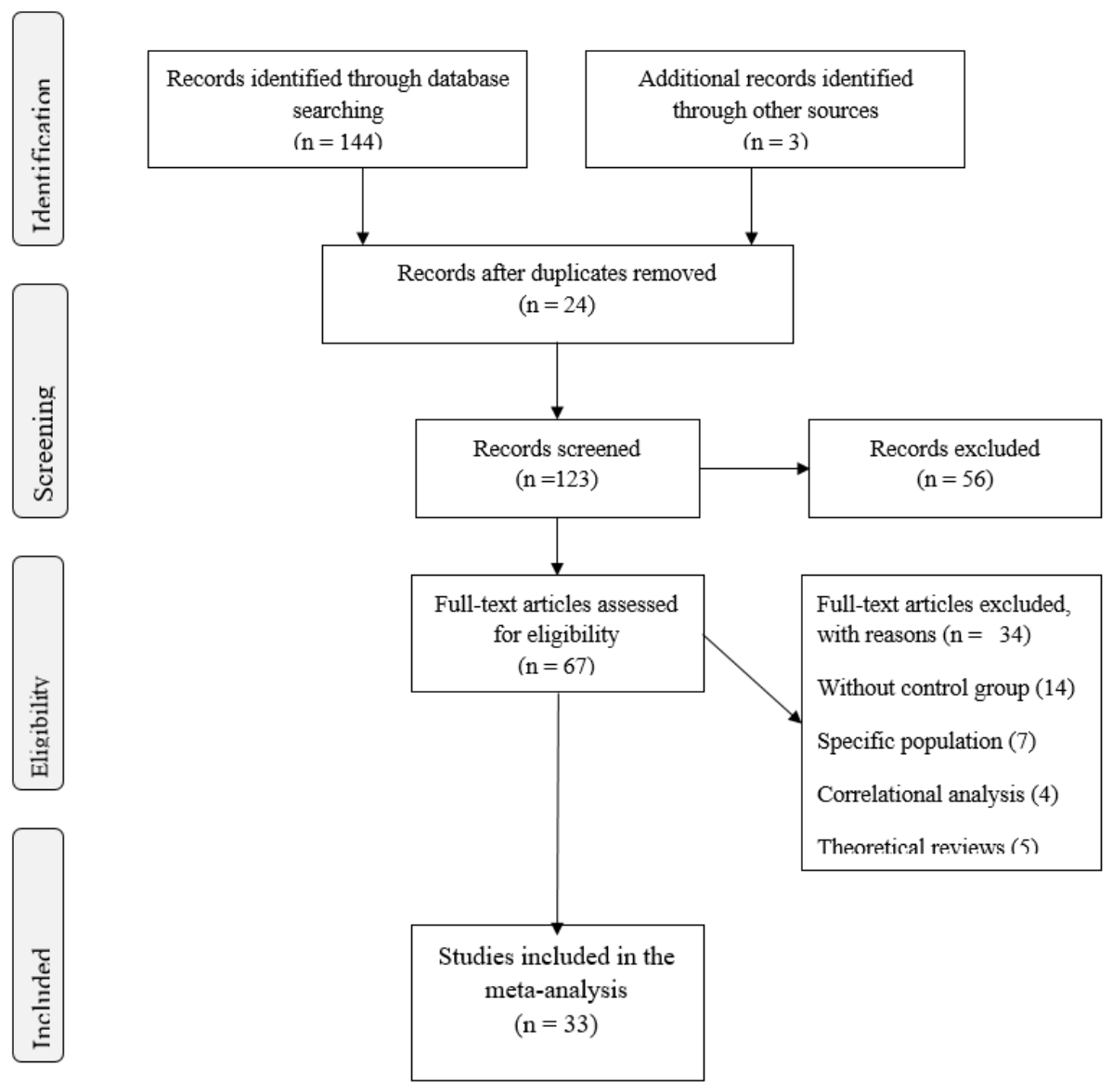

Figure 1. The Prisma flow diagram

\section{Procedure}

For the studies selected for meta-analysis we included in the systematic review the following information's: Identification of the study (first author and the year of the publication), the percentage of the masculine gender involved in the study, the country in which the program was conducted, the mean age of the participants, the educational cycle in which the subjects were enrolled, socio-economic status of the subjects, the total number of subjects included in the study at the beginning of the program, the final number of the subjects at the end of the program, type of the study, level of randomization, type of control group, number of sessions included in the program, the duration of a program session, total duration of the program in hours, total duration of the program in weeks, weekly fervency of the meetings, type of facilitator.

Part of the outcome measures presented below was borrowed from Durlak et al. (2011), with the mention that we changed emotional distress to more specific outcome called internalizing problems, and conduct problems with externalizing problems:
Social and emotional skills. This category includes assessments of different types of social, emotional and cognitive skills that are related to issues such as emotion identification, social indices, goal setting, interpersonal problem solving, conflict resolution, decision making. These competencies can be reported by the child, teacher, parent or independent observer. Dependent variables in this category reflect skill acquisition or performance measured in test or structured tasks.

Attitudes toward self and others. This category combines positive attitudes towards oneself, school, or other social issues. Factors of self-perception (e.g., selfesteem, self-perception and self-efficacy), links to school (e.g., attitudes towards school and teachers), and conventional (pro-social) beliefs about violence, helping others, social justice, and drug use. All results in this category were based on the self-report responses of the subjects. We combined these three results to avoid detailed analyzes.

Positive Social Behavior. This category included results as a good relationship with each other, derived from both students, teachers, parents, and an independent observer. These results reflect daily behavior rather than 
performance in hypothetical situations, which was quoted as a result of social-emotional abilities. For example, teacher's scoring on social abilities extracted from the Scale of Social Ability of Elliott and Gresham's (Elliot, Gresham, Freeman, \& McCloskey, 1988), were included in the category of social and emotional skills.

Externalizing problems. This category includes measurements of various types of behavioral problems such as disturbing behaviors in the classroom, lack of compliance, aggression, bullying, expulsion, and delinquency. These measurements can be made by student self-report, teachers, parents, independent scholars, or, for example, using school documents in the cases of expelling.

Internalizing problems. This category is comprised of measuring internalized mental health issues. This includes depression, anxiety, stress, or social withdrawal, data that can be collected from students, teachers, or parents.

\section{Analytical procedure}

For the calculation of the effect sizes, we used Hedge's g. A value of Hedge's $g$ between .20 and .50 indicates a small effect, between .50 and .80 indicates a medium effect, and a value higher than .80 indicates a large effect (Cohen, 1988) From the studies included in the metaanalysis we collected the mean scores, standard deviations, and sample size. To test for heterogeneity of the effect sizes, we considered two statistics: the homogeneity test Q and the $\mathrm{I}^{2}$ index. To test for publication bias, we used the Duval and Tweedie's trim-and-fill procedure (Duval \& Tweedie, 2000).

\section{Results}

Table 1 presents effect sizes for the outcomes combined and separately. The combined effect size for all 37 prevention programs was $0.31(\mathrm{CI}=0.174$ to 0.437$)$ which was statistically significant from zero. The $Q$ value of
672.78 was significant and the $\mathrm{I}^{2}$ was high $(94.64 \%)$ indicating substantial heterogeneity among studies. Statistically significant effect size was obtained for prosocial behavior $(\mathrm{g}=.20, \mathrm{p}<.01,95 \% \mathrm{CI}=[0.055$; $0.339])$. There was also evidence of heterogeneity, $\mathrm{Q}=$ $32.29, \mathrm{p}<.01, \mathrm{I}^{2}=72.13$. In term of social and emotional skills, results revealed a statistically significant size effect $(\mathrm{g}=.36, \mathrm{p}<.01,95 \% \mathrm{CI}=[0.252 ; 0.470])$ with evidence of heterogeneity, $\mathrm{Q}=86.82, \mathrm{p}<.01, \mathrm{I}^{2}=74.662$. The largest effect size was reported by externalizing problems $(\mathrm{g}=.37, \mathrm{p}<.01,95 \% \mathrm{CI}=[0.176 ; 0.568])$ with a high indicator of heterogeneity, $\mathrm{Q}=658.81, \mathrm{p}<.01, \mathrm{I}^{2}=96.81$. Smaller effect sizes were registered by attitudes $(\mathrm{g}=.19, \mathrm{p}$ $<.05,95 \% \mathrm{CI}=[0.043 ; 0.334], \mathrm{Q}=14.98, \mathrm{p}<.01, \mathrm{I}^{2}=$ $59.95)$ and internalizing problems $(\mathrm{g}=.17, \mathrm{p}<.01,95 \% \mathrm{CI}$ $\left.=[0.068 ; 0.280], \mathrm{Q}=62.89, \mathrm{p}<.01, \mathrm{I}^{2}=72.96\right)$.

In Table 2 we present the analysis concerning the moderator involved in the study. To investigate the second objective, we performed moderation analysis for groups of age in relation to SEL programs. The age group consisting of youth aged between 7 and 12 reported the highest effect size $(\mathrm{g}=.38, \mathrm{p}<.01,95 \% \mathrm{CI}=[0.171 ; 0.591], \mathrm{Q}=$ $\left.503.22, \mathrm{p}<.01, \mathrm{I}^{2}=96.82\right)$. The group of youth aged $3-6$ had a small significant effect size $(\mathrm{g}=.31, \mathrm{p}<.01,95 \% \mathrm{CI}$ $=[0.196 ; 0.422])$ but in terms of heterogeneity the results were not significant $\left(\mathrm{Q}=16.21, \mathrm{p}>.05, \mathrm{I}^{2}=38.33\right)$. The group of adolescents aged 13 to 18 didn't reveal a significant effect size $(\mathrm{g}=.13, \mathrm{p}>.05,95 \% \mathrm{CI}=[-0.019$; $\left.0.280], \mathrm{Q}=30.63, \mathrm{p}<.01, \mathrm{I}^{2}=73.88\right)$.

\section{Publication bias}

For the comparison of intervention groups with control groups on the efficiency of SEL programs, the trim-and-fill procedure identified no studies with a higher effect size than the mean which could affect the results. Thus, the analysis appears to be robust and not affected by publication bias.

Table 1. Effects sizes, heterogeneity and Confidence Intervals for the outcomes ivolved in the study

\begin{tabular}{lllllll}
\hline Outcomes & $N$ & $g$ & $Q$-within & $p$ & $C I$ & $I^{2}$ \\
\hline Attitudes & 7 & .19 & 14.98 & .02 & {$[0.043 ; 0.334]$} & 59.95 \\
Prosocial behavior & 10 & .20 & 32.29 & .00 & {$[0.055 ; 0.339]$} & 72.13 \\
Social and emotional skills & 23 & .36 & 86.82 & .00 & {$[0.252 ; 0.470]$} & 74.66 \\
Externalizing problems & 22 & .37 & 658.81 & .00 & {$[0.176 ; 0.568]$} & 96.81 \\
Internalizing problems & 18 & .17 & 62.89 & .00 & {$[0.068 ; 0.280]$} & 72.96 \\
Outcomes combined & 37 & .31 & 672.78 & .00 & {$[0.174 ; 0.437]$} & 94.64 \\
\hline Note: $\mathrm{N}=$ number of studies, $\mathrm{g}=$ Hedge's $\mathrm{g}$; $\mathrm{CI}=95 \%$ confidence interval & & &
\end{tabular}

Note: $\mathrm{N}=$ number of studies, $\mathrm{g}=$ Hedge's $\mathrm{g} ; \mathrm{CI}=95 \%$ confidence interval

Table 2. Moderation analysis with categorical with subgroups of age

\begin{tabular}{lllllll}
\hline Moderator & $N$ & $g$ & $Q$-within & $p$ & $C I$ & $I^{2}$ \\
\hline 3-6 years & 11 & .31 & 16.21 & .00 & {$[0.196 ; 0.422]$} & 38.33 \\
7-12 years & 17 & .38 & 503.22 & .00 & {$[0.171 ; 0.591]$} & 96.82 \\
13-18 years & 9 & .13 & 30.63 & .08 & {$[-0.019 ; 0.280]$} & 73.88 \\
\hline
\end{tabular}

Note: $\mathrm{N}=$ number of studies, $\mathrm{g}=$ Hedge's $\mathrm{g} ; \mathrm{CI}=95 \%$ confidence interval 


\section{Discussion}

The main objective of this study was to investigate the impact of SEL programs on reducing internalizing and externalizing problems and the potential to increase social and emotional skills, prosocial behaviors and attitudes in the youth population. Overall, the results obtained confirmed the stability of the effect size produced by SEL programs on different outcomes. As in the previous metaanalysis concerning school-based SEL programs (Durlak et al., 2011), the effect size was statistically significant but small $(\mathrm{g}=.31)$. Scientific literature suggests that SEL programs can reduce both internalizing and externalizing problems in youth by enhancing them with social and emotional skills (Greenberg et al., 2003; Lewis et al., 2013; Schonert-Reichl et al., 2015; Coelho et al., 2015). The results from this meta-analysis support only partially the previous findings. On the positive side, externalizing problems were reduced by SEL programs, results reporting a small to medium effect size $(\mathrm{g}=.37)$. On the less positive side, internalizing problems yield an insignificant effect size $(g=.17)$. Internalizing problems can prove to be more difficult to change because of its internal behaviors that can often be missed by others. In contrast, externalizing problems are evident for specialists and can be dealt with more often. Significant results were obtained for the development of social and emotional skills through SEL programs. The effect size was small but significant $(g=$ .36). The previous meta-analysis reported a medium effect size for social and emotional skills. Despite the small number of studies reposting outcomes related to prosocial behavior and attitudes toward self and others, the effect sizes were statistically significant $(g=.20$ and $g=.19)$.

The moderator introduced in this meta-analysis was the age of the subjects, more specific the grouping of the subjects in three variables (3-6 years, 7-12 years and 13-18 years). Participant's age appeared to be significant in the process of assimilating the competencies and information delivered by SEL programs. The age group that seems to enhance more effectively the social and emotional skills along with other positive behaviors is the second group, youth aged between 7 and 12. The effect size for this group was statistically significant $(\mathrm{g}=$ .38). Around this age is the period where the children are starting to become more independent and to form their own identity. The other two groups (3-6 years and 13-18) have obtained mixed results. Although the age group consisting of children from 3 to 6 years old reported a significant effect size $(g=.31)$, the heterogeneity was very low, indicating that there is a great possibility of other moderators that can influence the result. The group formed by adolescents was the reporting the smallest effect size ( $g$ $=.13$ ), and also statistically insignificant.

The findings of this meta-analysis are suggesting that SEL programs have not lost their significance in the development of certain competencies and reducing emotional and behavioral problems. Still, no change was registered on the combine outcomes, from 2008 (the year of Durlak's meta-analysis) until today. SEL programs continued to have an impact on the life of children and adolescents, but the effect is small if we take into consideration the effect sizes. For practical purposes, SEL should still be viewed as a solution for preventing social and emotional problems in the youth population.

\section{Limitations and future directions}

As any study, this one is not without limitations. Firstly, we have to mention the small number of studies involved in this meta-analysis compared to the previous one. A more comprehensive search would be needed. Secondly, the lack of more moderators that could provide a better explanation of the results obtained. Involving new moderators, such as the type of program and the type of activities delivered to youth, could improve our understanding of the results. Thirdly, the lack of academic achievement as an outcome also impacts our results in a negative manner. Lastly, a more specific categorization of the outcomes could have been made.

\section{References}

References marked with an asterisk indicate studies included in the meta-analysis.

Bamford, C., \& Lagattuta, K. H. (2012). Looking on the bright side: Children's knowledge about the benefits of positive versus negative thinking. Child Development, 83(2), $667-$ 682, https://doi.org/10.1111/j.1467-8624.2011.01706.x

Bavarian, N., Lewis, K. M., DuBois, D. L., Acock, A., Vuchinich, S., Silverthorn, N., Snyder, F. J., Day, J., Ji, P., \& Flay, B. R. (2013). Using social-emotional and character development to improve academic outcomes: A matched-pair, cluster-randomized trial in low-income, urban schools. Journal of School Health, 83, 771-779, https://doi.org/10.1111/josh.12093

Bear, G. G., \& Minke, K. M. (2006). Children's needs III: Development, prevention, and intervention. National Association of School Psychologists.

Benson, P. L. (2006). All kids are our kids: What communities must do to raise caring and responsible children and adolescents. Jossey-Bass.

*Bierman, K. L., Nix, R. L., Greenberg, M. T., Blair, C., \& Domitrovich, C. E. (2008). Executive functions and school readiness intervention: Impact, moderation, and mediation in the Head Start REDI program. Development and psychopathology, 20(3), 821-843, https://doi.org/10.1017/S0954579408000394

Bradley, R. T., Galvin, P., Atkinson, M., \& Tomasino, D. (2012). Efficacy of an emotion self-regulation program for promoting development in preschool children. Global Advances in Health and Medicine, 1(1), 36-50, https://doi.org/10.7453/gahmj.2012.1.1.010

*Brackett, M. A., Rivers, S. E., Reyes, M. R., \& Salovey, P. (2012). Enhancing academic performance and social and emotional competence with the RULER feeling words curriculum. Learning and Individual Differences, 22(2), 218-224, https://doi.org/10.1016/j.lindif.2010.10.002

*Caldarella, P., Christensen, L., Kramer, T. J., \& Kronmiller, K. (2009). Promoting social and emotional learning in second grade students: A study of the Strong Start curriculum. Early Childhood Education Journal, 37(1), 51-56, https://doi.org/10.1007/s10643-009-0321-4

*Castillo, R., Salguero, J. M., Fernández-Berrocal, P., \& Balluerka, N. (2013). Effects of an emotional intelligence intervention on aggression and empathy among adolescents. Journal of Adolescence, 36(5), 883-892, https://doi.org/10.1016/j.adolescence.2013.07.001

*Choque-Larrauri, R., \& Chirinos-Cáceres, J. L. (2009). Eficacia del Programa de habilidades para la vida en adolescentes escolares de Huancavelica, Perú. Revista de Salud pública, 11(2). 
*Coelho, V. A., Marchante, M., \& Sousa, V. (2015). "Positive Attitude": A multilevel model analysis of the effectiveness of a Social and Emotional Learning Program for Portuguese middle school students. Journal of adolescence, 43 , 29-38, https://doi.org/10.1016/j.adolescence.2015.05.009

*Coelho, V., Sousa, V., \& Figueira, A. P. (2014). The impact of a school-based social and emotional learning program on the self-concept of middle school students. Revista de Psicodidáctica, https://doi.org/0.1387/RevPsicodidact.10714

Cohen, J. (1988). Statistical power analysis for the behavioral sciences . Hilsdale. NJ: Lawrence Earlbaum Associates, 2.

Cordova, D., Estrada, Y., Malcolm, S., Huang, S., Brown, C. H., Pantin, H., \& Prado, G. (2014). Prevention science: An epidemiological approach. In Defining prevention science (pp. 1-23). Springer US.

*Daunic, A., Corbett, N., Smith, S., Barnes, T., SantiagoPoventud, L., Chalfant, P., ... \& Gleaton, J. (2013). Brief report: Integrating social-emotional learning with literacy instruction: An intervention for children at risk for emotional and behavioral disorders. Behavioral Disorders, $39(1)$,

43-51, https://doi.org/10.1177/019874291303900106

Durlak, J. A., \& Wells, A. M. (1997). Primary prevention mental health programs for children and adolescents: A meta - analytic review. American journal of community psychology, 25(2),

115-152, https://doi.org/10.1023/A:1024654026646

Durlak, J. A., Weissberg, R. P., \& Pachan, M. (2010). A meta - analysis of after-school programs that seek to promote personal and social skills in children and adolescents. American journal of community psychology, 45(3-4), 294-309, https://doi.org/10.1007/s10464-010-9300-6.

Durlak, J. A., Weissberg, R. P., Dymnicki, A. B., Taylor, R. D., \& Schellinger, K. B. (2011). The impact of enhancing students' social and emotional learning: A meta - analysis of school - based universal interventions. Child development, 82(1), 405-432, https://doi.org/10.1111/j.1467-8624.2010.01564.x

Duval, S., \& Tweedie, R. (2000). Trim and fill: A simple funnel-plot-based method of testing and adjusting for publication bias in meta-analysis. Biometrics, 56, 455463. doi:10.1111/j.0006-341X.2000.00455.x

Finan, L. J., Schulz, J., Gordon, M. S., \& Ohannessian, C. M. (2015). Parental problem drinking and adolescent externalizing behaviors: The mediating role of family functioning. Journal of adolescence, 43, 100-110, https://doi.org/10.1016/j.adolescence.2015.05.001

*Garaigordobil, M., \& Peña-Sarrionandia, A. (2015). Effects of an emotional intelligence program in variables related to the prevention of violence. Frontiers in psychology, 6 , 10.3389/fpsyg.2015.00743

Goleman, D. P. (1995). Emotional intelligence: Why it can matter more than IQ for character, health and lifelong achievement

Greenberg, M. T., Weissberg, R. P., O'brien, M. U., Zins, J. E., Fredericks, L., Resnik, H., \& Elias, M. J. (2003). Enhancing school-based prevention and youth development through coordinated social, emotional, and academic learning. American psychologist, 58(6-7), 466, http://dx.doi.org/10.1037/0003-066X.58.6-7.466

*Gueldner, B., \& Merrell, K. (2011). Evaluation of a socialemotional learning program in conjunction with the exploratory application of performance feedback incorporating motivational interviewing techniques. Journal of Educational and Psychological Consultation, 21(1),

$1-27$
Guerra, N. G., \& Bradshaw, C. P. (2008). Linking the prevention of problem behaviors and positive youth development: Core competencies for positive youth development and risk prevention. New directions for child and adolescent development, 2008(122), 1-17, http://dx.doi.org/10.1002/cd.225

Guo, J., Hawkins, J. D., Hill, K. G., \& Abbott, R. D. (2001). Childhood and adolescent predictors of alcohol abuse and dependence in young adulthood. Journal of studies on alcohol, 62(6),

754-762, https://doi.org/10.15288/jsa.2001.62.754.

*Gunter, L., Caldarella, P., Korth, B. B., \& Young, K. R. (2012). Promoting social and emotional learning in preschool students: A study of Strong Start Pre-K. Early Childhood Education Journal, 40(3), 151-159, https://doi.org/10.1007/s10643-012-0507-z

*Hassan, K. E., \& Mouganie, Z. (2014). Implementation of the Social Decision-Making Skills Curriculum on primary students (Grades 1-3) in Lebanon. School Psychology International, 35(2), 167-175, https://doi.org/10.1177/0143034312469758

Humphrey, N., Kalambouka, A., Wigelsworth, M., \& Lendrum, A. (2010). Going for goals: An evaluation of a short, social-emotional intervention for primary school children. School Psychology International,31(3), 250270, https://doi.org/10.1177/0143034309352578

Kerr, M., \& Stattin, H. (2000). What parents know, how they know it, and several forms of adolescent adjustment: further support for a reinterpretation of monitoring. Developmental psychology,36(3), 366 http://dx.doi.org/10.1037/0012-1649.36.3.366.

Klasen, F., Otto, C., Kriston, L., Patalay, P., Schlack, R., Ravens-Sieberer, U., \& Bella Study Group. (2015). Risk and protective factors for the development of depressive symptoms in children and adolescents: results of the longitudinal BELLA study. European child \& adolescent psychiatry, 24(6), http://dx.doi.org/10.1007/s00787-014-0637-5

*Kramer, T. J., Caldarella, P., Young, K. R., Fischer, L., \& Warren, J. S. (2014). Implementing Strong Kids schoolwide to reduce internalizing behaviors and increase prosocial behaviors. Education and Treatment of Children, 37(4), 659-680.

*Little, M., Berry, V., Morpeth, L., Blower, S., Axford, N., Taylor, R., ... \& Tobin, K. (2012). The impact of three evidence-based programmes delivered in public systems in Birmingham, UK. International Journal of Conflict and Violence (IJCV), 6(2), 260-272, http://dx.doi.org/10.4119/UNIBI/ijcv.263

*McCormick, M. P., O’Connor, E. E., Cappella, E., \& McClowry, S. G. (2015). Getting a good start in school: Effects of INSIGHTS on children with high maintenance temperaments. Early Childhood Research Quarterly, 30, 128-139, https://doi.org/10.1016/j.ecresq.2014.10.006

*McClowry, S. G., Snow, D. L., Tamis-LeMonda, C. S., \& Rodriguez, E. T. (2010). Testing the efficacy of INSIGHTS on student disruptive behavior, classroom management, and student competence in inner city primary grades. School mental health, 2(1), 23-35, http://dx.doi.org/10.1007/s12310-009-9023-8

Mills, C., Stephan, S. H., Moore, E., Weist, M. D., Daly, B. P., \& Edwards, M. (2006). The President's New Freedom Commission: Capitalizing on opportunities to advance school-based mental health services. Clinical Child and Family Psychology Review, 9(3-4), 149, http://dx.doi.org/10.1007/s10567-006-0003-3

*Moreira, P., Crusellas, L., Sá, I., Gomes, P., \& Matias, C. (2010). Evaluation of a manual-based programme for the promotion of social and emotional skills in elementary school children: Results from a 4-year study in Portugal. 
Health promotion international, 25(3), 309-317, https://doi.org/10.1093/heapro/daq029

* Munsawaengsub, C., Munsawaengsub, C., Yimklib, S., Nanthamongkolchai, S., Nanthamongkolchai, S., Apinanthavech, S., ... \& Apinanthavech, S. (2009). Effect of promoting self-esteem by participatory learning process on emotional intelligence among early adolescents. $J \mathrm{Med}$ Assoc Thai 92 Suppl. 7

*Muñoz de Morales Ibáñez, M., \& Bisquerra Alzina, R. (2013). Diseño, aplicación y evaluación de un plan de educación emocional en Guipúzco: análisis cuantitativo= Desing, implementation and evaluation of an emotional education plan in Guipúzcoa: quantitative analysis.

*Muratori, P., Bertacchi, I., Giuli, C., Lombardi, L., Bonetti, S., Nocentini, A., ... \& Lochman, J. E. (2015). First adaptation of Coping Power program as a classroom-based prevention intervention on aggressive behaviors among elementary school children. Prevention science, 16(3), 432-439, http://dx.doi.org/10.1007/s11121-014-0501-3

*Myles-Pallister, J. D., Hassan, S., Rooney, R. M., \& Kane, R. T. (2014). The efficacy of the enhanced Aussie Optimism Positive Thinking Skills Program in improving social and emotional learning in middle childhood. Frontiers in psychology, 5, https://doi.org/10.3389/fpsyg.2014.00909

*O'Connor, E. E., Cappella, E., McCormick, M. P., \& McClowry, S. G. (2014). An examination of the efficacy of INSIGHTS in enhancing the academic and behavioral development of children in early grades. Journal of Educational Psychology, 106(4), 1156, http://dx.doi.org/10.1037/a0036615

*Pendry, P., Carr, A. M., Smith, A. N., \& Roeter, S. M. (2014). Improving adolescent social competence and behavior: A randomized trial of an 11-week equine facilitated learning prevention program. The journal of primary prevention, 35(4), 281-293, http://dx.doi.org/10.1007/s10935-014-0350-7

Perou, R., Bitsko, R. H., Blumberg, S. J., Pastor, P., Ghandour, R. M., Gfroerer, J. C., ... \& Parks, S. E. (2013). Mental health surveillance among children-United States, 20052011. MMWR Surveill Summ, 62(Suppl 2), 1-35.

Resnick, M. D., Bearman, P. S., Blum, R. W., Bauman, K. E., Harris, K. M., Jones, J., ... \& Ireland, M. (1997). Protecting adolescents from harm: findings from the National Longitudinal Study on Adolescent Health. Jama, 278(10), 823-832, http://dx.doi.org/10.1001/jama.1997.03550100049038

Ryan, S. M., Jorm, A. F., \& Lubman, D. I. (2010). Parenting factors associated with reduced adolescent alcohol use: a systematic review of longitudinal studies. Australian \& New Zealand Journal of Psychiatry, 44(9), 774-783, http://dx.doi.org/10.1080/00048674.2010.501759.

*Ruiz-Aranda, D., Castillo, R., Salguero, J. M., Cabello, R., Fernández-Berrocal, P., \& Balluerka, N. (2012). Short-and midterm effects of emotional intelligence training on adolescent mental health. Journal of Adolescent Health, 51(5), https://doi.org/10.1016/j.jadohealth.2012.02.003

*Schonert-Reichl, K. A., Oberle, E., Lawlor, M. S., Abbott, D., Thomson, K., Oberlander, T. F., \& Diamond, A. (2015). Enhancing cognitive and social-emotional development through a simple-to-administer mindfulnessbased school program for elementary school children: A randomized controlled trial. Developmental psychology, 51(1), 52, http://dx.doi.org/10.1037/a0038454

*Schonert-Reichl, K. A., Smith, V., Zaidman-Zait, A., \& Hertzman, C. (2012). Promoting children's prosocial behaviors in school: Impact of the "Roots of Empathy" program on the social and emotional competence of school-aged children. School Mental Health, 4(1), 1-21, 10.1007/s12310-011-9064-7

*Schonert-Reichl, K. A., \& Lawlor, M. S. (2010). The effects of a mindfulness-based education program on pre-and early adolescents' well-being and social and emotional competence. Mindfulness, 1(3), 137-151, http://dx.doi.org/10.1007/s12671-010-0011-8

*Sheridan, S. M., Knoche, L. L., Edwards, C. P., Bovaird, J. A., \& Kupzyk, K. A. (2010). Parent engagement and school readiness: Effects of the Getting Ready intervention on preschool children's social-emotional competencies. Early Education and Development, 21(1), 125-156, http://dx.doi.org/10.1080/10409280902783517

Shochet, I. M., Dadds, M. R., Ham, D., \& Montague, R. (2006). School connectedness is an underemphasized parameter in adolescent mental health: Results of a community prediction study. Journal of Child and Adolescent Psychology, 35, 170-179, http://dx.doi.org/10.1207/s15374424jccp3502_1

*Snyder, F., Flay, B., Vuchinich, S., Acock, A., Washburn, I., Beets, M., \& Li, K. K. (2009). Impact of a socialemotional and character development program on schoollevel indicators of academic achievement, absenteeism, and disciplinary outcomes: A matched-pair, clusterrandomized, controlled trial. Journal of Research on Educational Effectiveness, 3(1), 26-55, http://dx.doi.org/10.1080/19345740903353436

*Upshur, C., Wenz-Gross, M., \& Reed, G. (2013). A pilot study of a primary prevention curriculum to address preschool behavior problems. The journal of primary prevention, $34(5)$, http://dx.doi.org/10.1007/s10935-013-0316-1

Vaughn, M. G., Salas-Wright, C. P., DeLisi, M., \& Maynard, B. R. (2014). Violence and externalizing behavior among youth in the United States: Is there a severe 5\%? Youth Violence and Juvenile Justice, 12(1), 3-21, http://dx.doi.org/10.1177/1541204013478973

*Webster - Stratton, C., Jamila Reid, M., \& Stoolmiller, M. (2008). Preventing conduct problems and improving school readiness: evaluation of the incredible years teacher and child training programs in high - risk schools. Journal of child psychology and psychiatry, 49(5), 471-488, http://dx.doi.org/10.1111/j.1469-7610.2007.01861.x

Weissberg, R. P., \& Cascarino, J. (2013). Academic learning+ social-emotional learning $=$ national priority. Phi Delta Kappan, 95(2), http://dx.doi.org/10.1177/003172171309500203

*Westhues, A., Hanbidge, A. S., Gebotys, R., \& Hammond, A. (2009). Comparing the effectiveness of school-based and community-based delivery of an emotional regulation skills program for children. School Social Work Journal, 34(1), 74-95

*Wigelsworth, M., Humphrey, N., \& Lendrum, A. (2013). Evaluation of a school-wide preventive intervention for adolescents: The secondary social and emotional aspects of learning (SEAL) programme. School Mental Health, 5(2), 96-109, http://dx.doi.org/10.1007/s12310-012-9085$\mathrm{x}$

Zins, J. E., Bloodworth, M. R., Weissberg, R. P., \& Walberg, H. J. (2004). The scientific base linking social and emotional learning to school success. Building academic success on social and emotional learning: What does the research say, 3-22.

Woolley, J. D., Boerger, E. A., \& Markman, A. (2004). A visit from the Candy Witch: Children's belief in a novel fantastical entity. Developmental Science, 7, 456-468. doi: $10.1111 / \mathrm{j} .1467-7687.2004 .003$ 